\title{
https://doi.org/10.48009/1_iis_2005_176-182
}

\section{EFFECTIVENESS OF HYBRID LEARNING ENVIRONMENTS}

\author{
Omar El-Gayar, Dakota State University, omar.el-gayar@dsu.edu \\ Terry Dennis, Illinois State University, tdennis@ilstu.edu
}

\begin{abstract}
Hybrid learning environment (HLE) is a classroom-and computer-based environment that is an open system, allowing synchronous and asynchronous interactions and encounters with other participants. This paper assesses the learning effectiveness of students in HLE for two core MSIS courses at DSU. In conclusion, the results attest to the viability of HLE. In-class and video conferencing students get to benefit from the virtual classroom setting (supporting web-site, asynchronous communication via electronic discussion board and email, and the opportunity to review the recorded class), while Internet students get to benefit by reducing the anxiety and feeling of isolation through the opportunity to feel and experience the classroom setting. HLE affords alternative delivery mechanisms, thereby accommodating various learning models.
\end{abstract}

Keywords: Information systems education, Hybrid learning environment, Distance education

\section{INTRODUCTION}

Distance education can be traced back to 1969, with the advent of the open university in the United Kingdom. Nevertheless, it has not been until the nineties that distance education became popular on colleges, universities, and business organizations alike. The explosive growth of distance education is largely attributed to the changing needs of the population and enabled by the advancement in information technology (IT). According to Khirallah [11], 50\% of all employees' skills become outdated within 3-5 years and that 'time to competency' is a major factor for determining competitiveness. Moreover, in 1999, companies spent $\$ 62.5$ billion on training and education in the United States with $\$ 3$ billion spent on technology-driven education. In effect, technology enabled distance education addresses the growing needs for time and location flexibility, cost and time savings, self-paced, learner centric learning, collaborative learning environments, and unlimited access to learning material [18, 23].

Distance education comes in different forms and flavors and can be classified along multiple dimensions including type of communication (synchronous versus asynchronous), place, and technology to name a few. In this paper we define distance education in terms of the learning environment it supports, where a learning environment refers to a particular setting in which learning takes place. Examples of learning environments include a traditional classroom-based environment, computer assisted instruction, a virtual learning environment (VLE), and a hybrid learning environment (HLE).

In computer aided instruction, students individually enter a self-contained computer-based learning environment with little if any communication among students or between students and the instructor [14]. In contrast, Wilson [21] defines VLE as "computer-based environments that are relatively open systems, allowing interactions with the participant." With the advent of the Internet, VLEs usually refer to Internet-based environments that allow for either synchronous or 
asynchronous communication. Hybrid learning environment (HLE) refers to a classroom- and computer-based environment that is a relatively open system, allowing synchronous and asynchronous interactions and encounters with other participants.

While a great deal of research has been done in determining and evaluating learning effectiveness, not much research has been done assessing the efficacy of HLE. With the potential of HLE to offer the best of the two worlds (traditional classroom environment and VLE), there is a distinct need to formally assess the learning effectiveness of students in such environment. This paper is a contribution towards this goal.

The paper is organized as follows: the following section presents a brief review of related work with particular emphasis on the effectiveness of technology-enabled distance education and contemporary learning theories. Next, we investigate and report on the efficacy of HLE. We then conclude the paper and highlight limitations and avenues for extending our research.

\section{RELATED WORK}

Developing and evaluating the effectiveness of various learning environments and supporting technology explicitly or implicitly assumes a particular learning model. Following Leidner and Jarvenpaa [12], a fundamental premise in learning effectiveness of various technologies is how well the technology supports a particular model of learning. In their paper, the authors identify and discuss a number of the more widely accepted models, a number of information technologies and provide a framework mapping the technologies to the learning model. For example, technologies such as 'instructor console', computer-assisted instruction (CAI) supports the objectivist model where learning is instructor centric and the goal is to transfer knowledge from the instructor to the student. On the other hand, for cognitive models such as constructivist and collaborative learning models in which involvement is critical to learning, technologies such as the Internet, simulation, groupware, and synchronous communication classrooms can contribute to students' learning [12].

Other theoretical frameworks include those proposed by Picolli et al. [14] for VLE and Dennis et al. [5] for HLE. Picolli et al. [14] developed an initial conceptualization of the determinants of learning effectiveness in a virtual learning environment. In this framework, factors affecting learning effectiveness in terms of performance, self-efficacy, and satisfaction can be classified according to a human and a design dimension. The human dimension reflects student attributes such as maturity and motivation, and instructor attributes such as teaching style and availability. The design dimension reflects the choice of the underlying learning model (consistent with 12), and various design attributes pertaining to technology, learner control, course content, and the level of interaction. Dennis et al. [5] extends Picolli et al [14] framework to explicitly capture the role of the learning environments in learning effectiveness as well as the interdependency among various determinants of learning effectiveness.

With regard to empirical research on VLE, Picolli et al. [14] report that (in the context of basic IT skills training in undergraduate education) while there are no significant differences in performance compared to a traditional classroom setting, VLE leads to higher reported computer self-efficacy but less satisfaction with the learning process. Rivera and McAlister [16] also 
reported similar findings. Other related research confirmed the improvement in student learning $[7,9,10,13,17,20]$, while Thompson and Zhang [19, 22] report an improvement in student learning in VLE under certain conditions. On the other hand, reported drawbacks of VLE include feelings of isolation [4]; anxiety created by unfamiliar learning environment $[8,15]$ and diminished interest in the subject matter [13].

In support of collaborative learning, Alavi [1] concluded that using group decision support systems (GDSS) in a collaborative learning process provided higher levels of perceived skill development, self-reported learning, and evaluation of classroom experience. In addition, Alavi et al. [2] concluded that desktop video conferencing (DVC) was equally effective to traditional face-to-face collaborative learning environments with regard to knowledge acquisition and students' satisfaction with learning outcomes. Benbunan-Fich [3] also studied technology support for collaborative work. Their findings indicate that while there is a better perception of learning from the interaction of teamwork and asynchronous computer-support, there are no significant differences in exam results.

\section{HYPOTHESES}

The review of the theoretical and empirical literature indicates that different learning environments and enabling information technologies emphasize different learning models. Moreover, potential drawbacks in particular environments such as students' feeling of isolation in VLE do not exist in other environments such as the traditional classroom. Accordingly, by providing a traditional classroom setting and a VLE, HLE can potentially offer the better of the two worlds (traditional classroom environment and VLE). A fundamental question then is investigating how the learning effectiveness of HLE compares to VLE and the traditional classroom environment. However, before attempting to answer this question, we need to verify that there are no significant differences in the learning effectiveness of groups of students in a HLE. Specifically, we seek to test the following research hypotheses:

H1: The learning effectiveness of HLE students who meet face to face is not significantly different from the learning effectiveness of HLE students who meet via video conferencing facilities.

H2: The learning effectiveness of HLE students who meet via the video conferencing facilities is not significantly different than the learning effectiveness of HLE students who meet via the Internet.

H3: The learning effectiveness of HLE students who meet face to face is not significantly different than the learning effectiveness of HLE students who meet via the Internet

\section{METHODOLOGY}

The Master of Science in Information Systems (MSIS) program at Dakota State University (DSU) utilizes a HLE. In this environment, courses are taught as in-class courses using the oncampus Dakota Digital Network (DDN) classroom/studio, as remote sites using remote DDN classrooms (within the State of South Dakota), and live and/or video-streamed via the Internet. Internet students can still watch the classes, which are recorded digitally.

In this research we survey MSIS graduate students who have successfully completed two core MSIS courses over two semester by the same instructors. The rational for choice include: 
- Both are core classes with a large number of students (in excess of 35 students) spanning in-class, DDN, and Internet students. A large number of students are required for the validity of the results.

- Both classes required students to work in teams, thereby involved extensive group work. Working in teams is an essential component in preparing our students for their future professional careers, and is a particularly challenging element in HLE.

- Both classes involved the use of specialized software packages. By not being on campus, students miss out on the opportunity to gain one-on-one guidance on the use of the software packages.

\section{Subjects}

Overall, 137 students spanning both courses over two semesters were surveyed in the study. Students included a diverse group including international (on-campus), part-time, full-time, male and female students.

\section{Experimental design}

Initially, the experimental design comprised of two-factors: delivery method and Course. Delivery method included three levels: in-class (on-campus), DDN, and Internet, while Course included two levels: one for each course resulting in 3X2 factorial. However, due to insufficient data points for multivariate analysis and because of the similarity of the two courses in terms of structure, content, and pedagogical approach, we resorted to focus on Delivery method, i.e., oneway design.

\section{Dependent measures}

Consistent with the research literature, effective learning was measured in terms of two sets of variables: (1) satisfaction with the learning outcome, and (2) satisfaction with the learning process. Both variables were measured via Green and Taber's [6] satisfaction questionnaire. In this questionnaire, each variable was measured using five items on a five point Likert scale.

\section{RESULTS AND DISCUSSION}

Overall, a total of 86 responses were received. Careful examination of the data yielded 2 incomplete responses and 7 outliers. Outliers were identified graphically by super imposing an ellipse representing a 99\% confidence interval for bivariate normal distribution over a scatter plot for the two dependent measures. Furthermore, outliers were confirmed by calculating the Mahalanobis $\mathrm{D}^{2}$ measure which is a measure of the distance in multidimensional space of each observation from the mean center of the observations. In effect, we ended with 77 usable responses with means, standard deviation and sample sizes shown in Table 1 where P1 and P2 are the satisfaction with the learning outcome and satisfaction with the learning process, respectively.

Table 1. Sample Size, Mean \& Standard Deviations of Dependent Measures by Delivery Method

\begin{tabular}{|c|c|c|c|c|c|c|}
\hline & \multicolumn{2}{|c|}{ DDN } & \multicolumn{2}{|c|}{ In-class } & \multicolumn{2}{|c|}{ Internet } \\
\hline & P1 & P2 & P1 & P2 & P1 & P2 \\
\hline Mean & 3.7375 & 4.04 & 4.46 & 4.16 & 4.17 & 4.19 \\
\hline St. deviation & 0.583 & 0.546 & 0.524 & .803 & 0.611 & 0.466 \\
\hline Sample size & \multicolumn{2}{|c|}{16} & \multicolumn{2}{|c|}{26} & \multicolumn{2}{|c|}{35} \\
\hline
\end{tabular}


Given the unequal group sizes, statistical assumptions underlying multivariate analysis of variance (MANOVA) such as normality of the dependent measures in each group and homogeneity of variance becomes of paramount importance. Testing for normality using the Shapiro-Wilk test indicates that for P1 and P2 in the in-class group we reject the null hypothesis of normality at $1 \%$ significance level. Table 2 shows the p-value for all groups.

Table 2. p-values for the Shapiro-Wilk Test for Normality

\begin{tabular}{lcc}
\hline & P1 & P2 \\
\hline DDN & .35 & .098 \\
In-class & .004 & .0093 \\
Internet & .035 & .08
\end{tabular}

Using Levene's test for homogeneity of variance indicates that there is no significant difference among group variances. To correct for the non-normality of the dependent measures in the inclass group we transform the data by raising P1 and P2 to the power three, i.e., non-linear transformation. According to the Shapiro-Wilk test for normality, we cannot reject the null hypothesis regarding the normality of the variables in all three groups at $1 \%$ significance level. The corresponding p-values for the Shapiro-Wilk test are shown in Table 3.

Table 3. p-values for the Shapiro-Wilk test for Normality after a Non-Linear Transformation of the Dependent Variables

\begin{tabular}{lcc}
\hline & P1 & P2 \\
\hline DDN & .6155 & .036 \\
In-class & .012 & .0164 \\
Internet & .036 & .0135
\end{tabular}

Moreover, conducting Levene's test for homogeneity of variance on the transformed data set indicates that there is no significant difference among group variances. Performing MANOVA on the transformed data set indicate leads us to the conclusion that the mean vectors of the three groups are not equal at $1 \%$ significance level as shown in Table 4.

Table 4. Three-group MANOVA Summary Table

\begin{tabular}{lccccc}
\hline \multicolumn{1}{c}{ Statistic } & Value & F-value & Num DF & Den DF & p-value \\
\hline Wilks' Lambda & 0.805686 & 4.16 & 4 & 146 & 0.0032 \\
Pillai's criterion & 0.194354 & 3.98 & 4 & 148 & 0.0042 \\
Hotelling-Lawley & 0.24113 & 4.38 & 4 & 86.571 & 0.0028 \\
Roy's Greatest Root & 0.240927 & 8.91 & 2 & 74 & 0.0003
\end{tabular}

To identify whether group means are significantly different for each dependent variable considered alone, we conduct two ANOVA (one for each dependent variable). The results indicate that while there is a significant difference (at 1\%) among groups regarding the satisfaction with the learning outcome $(\mathrm{P} 2)$, there is no significant difference when it comes to satisfaction with the learning process.

Finally, to investigate whether the difference is among all three groups or among a subset of the three delivery methods, we conducted a Tukey's Studentized Range (HSD) Test for the dependent variable which indicated that for P1, in-class and Internet students are not 
significantly different from each other, but are different from DDN students. On the other hand, for P2, all three groups appear to have equal means, i.e., group means are not significantly different from one another.

\section{CONCLUSIONS}

This research indicates that with respect to satisfaction with the learning process, in-class, DDN, and Internet are not significantly different. While this result contradicts earlier studies such as Picolli et al. [14] and Rivera and McAlister [16] regarding the VLE, it depicts the potential advantage of HLE over VLE. In other words, the recording and video streaming of classes is an enhancement over just VLE where students may not get to feel or experience a classroom setting, even remotely. Moreover, with the exception of DDN, in-class and Internet student do not exhibit any difference when it comes to satisfaction with the learning outcome.

In conclusion, the results attest to the viability of HLE. In-class and DDN students get to benefit from the virtual classroom setting (supporting web-site, asynchronous communication via electronic discussion board and email, and the opportunity to review the recorded class), while Internet students get to benefit from the increased flexibility and availability offered by Internet courses, but with apparent reduced anxiety and feelings of isolation brought about by the opportunity to feel and experience the classroom setting. HLE affords alternative delivery mechanisms thereby accommodating various learning models.

\section{Limitations and Future Research}

The research can certainly take advantage of an expanded data set. This is particularly true with respect to the DDN group (16 responses) in which its size is half the Internet group, and significantly smaller than the in-class group. Another limitation that affects field research in general is the inability to control many of the factors that may exist in a real world pedagogical setting as in this research. Last but not least, the reliance on graduate (MSIS) students introduces two possible biases; namely, 1) graduate students are likely to be more mature learners, more self-motivated, and more self-disciplined. As such they may do better in HLEs than undergrads would, and 2) MSIS students are not as likely as other groups to be put off by the technologies involved. Future research includes accumulating additional responses to address the sample size limitation and evaluating HLE (in-class, DDN, and Internet, collectively as a group) against a strictly VLE as well as including undergraduate students.

\section{REFERENCES}

1. Alavi, M. (1994). Computer-mediated collaborative learning: An empirical evaluation. $M I S$ Quarterly, 18(2), 159.

2. Alavi, M., Wheeler, B. C., \& Valacich, J. S. (1995). Using IT to reengineer business education: An exploratory investigation of collaborative telelearning. MIS Quarterly, 19(3), 293.

3. Benbunan-Fich, R., \& Hiltz, S. R. (1999). Impacts of Asynchronous Learning Networks on Individual and Group Problem Solving: A Field Experiment. Group Decision and Negotiation, 8(5), 409.

4. Brown, K. (1996). The Role of Internal and External Factors in the Discontinuation of OffCampus Students. Distance Education, 17(1), 44-71.

5. Dennis, T., O.F. El-Gayar, and Z. Zhou (2002). A conceptual framework for hybrid distance delivery for information system programs. Issues in Information Systems (IIS), Volume III. 
6. Green, S. G., \& Taber, T. D. (1980). The effects three social decision schemes in decision group process. Organizational Behavior and Human Performance, 25, 97-106.

7. Hadidi, R., \& Sung, C. (2000). Pedagogy of online instruction - Can it be as good as face-toface? Proceedings of the Americas Conference of Information Systems, Long Beach, CA.

8. Hara, N., \& Kling, R. (2000). Students' Distress with a Web-Based Distance Education Course: An Ethnographic Study of Participants' Experiences. Information, Communication and Society, 3(4), 557-579.

9. Hiltz, S. R. (1995). Teaching in a virtual classroom. International journal of educational telecommunications, 1(2), 185-198.

10. Hiltz, S. R., \& Wellman, B. (1997). Asynchronous learning networks as a virtual classroom. Communications of the ACM, 40(9), 44.

11. Khirallah, D. R. (2002). A new way to learn. Information Week (889), 65.

12. Leidner, D. E., \& Jarvenpaa, S. L. (1995). The use of information technology to enhance management school education: A theoretical view. MIS Quarterly, 19(3), 265.

13. Maki, R., Maki, W., Patterson, M., \& Whittaker, P. (2000). Evaluation of a web-based introductory Psychology course: Learning and satisfaction in on-line versus lecture courses. Behavior Research Methods, Instruction, and Computers, 32(2), 230-239.

14. Piccoli, G., Rami, A., \& Ives, B. (2001). Web-based virtual learning environments: A research framework and a preliminary assessment of effectiveness in basic IT skills training. MIS Quarterly, 25(4), 401.

15. Ricketts, J., Wolfe, F., Norvelle, E., \& Carpenter, E. (2000). Asynchronous Distributed Education- a Review and Case Study. Social Science Computer Review, 18(2), 132-146.

16. Rivera, J., \& McAlister, M. (2001). A comparison of student outcomes and satisfaction between traditional and web-based course offerings. Proceedings of the 2001 Information Resources Management Accosiation International Conference, Ontario, Canada.

17. Schutte, J. G. (1997). Virtual teaching in higher education: The new intellectual superhighway or just another traffic jam, Accessed: 2004, from http://www.csun.edu/sociology/virexp.htm

18. Shneiderman, B., Alavi, M., Norman, K., \& Borkowski, E. Y. (1995). Windows of opportunity in electronic classrooms. Communications of the ACM, 38(11), 19.

19. Thompson, M. (1996). Distance delivery of raduate-level teacher-education: Beyond parity claims. Journal of Continuing Higher Education, 44(3), 29-34.

20. Wade, V. P., \& Power, C. (1998). Evaluating the design and delivery of WWW based educational environments and courseware. Proceedings of the ACM-SIGCSE and SIGCUE Annual Joint Conference Integrating Technology into Computer Science Education, Dublin City Univ., Ireland.

21. Wilson, B. (1996). Constructivist Learning Environments: Case Studies in Instructional Design. Englewood Cliffs, NJ: Educational Technology Publications.

22. Zhang, D. (2002). Media structuration - Towards an integrated approach to interactive multimedia-based E-Learning. University of Arizona.

23. Zhang, D., \& Nunamaker, J. F. (2003). Powering E-Learning In the New Millennium: An Overview of E-Learning and Enabling Technology. Information Systems Frontiers, 5(2), 207. 